\section{Estratégias de textualização na polêmica sobre culturas agrícolas no Brasil}

Textualization strategies in the
controversy over agricultural
crops in Brazil

Patrícia Sousa Almeida de MACEDO (UFPA) pat-alm@hotmail.com

Mônica Magalhães CAVALCANTE (UFC) monicamco2@gmail.com

Recebido em: 15 de out. de 2018. Aceito em: 22 de fev. de 2019.
MACEDO, Patrícia Sousa Almeida de; CAVALCANTE, Mônica Magalhães. Estratégias de textualização na polêmica sobre culturas agrícolas no Brasil. Entrepalavras, Fortaleza, v. 9, p. 303-320, n. 1, jan-abr/2019.

Resumo: Neste artigo, analisamos algumas formas de textualização da modalidade polêmica no debate, cada vez mais intenso no Brasil, a respeito de dois modelos agrícolas divergentes: o da agroecologia e o do agronegócio. A modalidade polêmica é uma das modalidades argumentativas apontadas por Ruth Amossy em seus escritos sobre a argumentação no discurso. As categorias de análise que a autora elege para o estudo da argumentatividade no discurso são, em sua maioria, de ordem linguística (termos lexicais, construções sintáticas, conectores etc.) e pragmática (implícitos, pressupostos e subentendidos). Nosso intuito é propor, neste trabalho, que a análise da argumentação no discurso tambémutilizecategorias deordem textual para o estudo da argumentatividade e, mais especificamente, da modalidade polêmica. Assim, apresentamos 0 gênero do discurso e a intertextualidade como critérios textuais possíveis de serem mobilizados para a análise da argumentatividade em interações que participam do debate polêmico contemporâneo em torno das duas culturas agrícolas supramencionadas. Do ponto de vista metodológico, optamos por analisar um texto, pertencente ao gênero 
V. 9 (1)

$303-320$

jan-abr

2019

charge, que faz parte da polêmica em tela. Nossa análise nos leva a: i) corroborar a tese de que a opção por um dado gênero consiste em uma estratégia de persuasão e ii) confirmar a hipótese de que é possível um texto desprovido de visada argumentativa participar ativamente de uma polêmica, desde que seja visto pelo prisma das relações intertextuais às quais ele alude. Além desses, outros critérios de textualização podem ser mobilizados para uma análise da argumentatividade polêmica.

Palavras-chave: Modalidade polêmica. Gênero do discurso. Intertextualidade.

Abstract: In this article, we analyze some forms of textualization of the controversial modality in the debate, more and more intense in Brazil, regarding two agricultural divergent models: agroecology and agribusiness. The controversial modality is one of the argumentative modalities pointed out by Ruth Amossy in her writings about the argumentation in the discourse. The categories of analysis choosed by the author to study argumentativity in discourse are mostly linguistic (lexical terms, syntactic constructions, connectors, etc.) and pragmatic (implicit, presupposed and implied). Our intention is to propose here that the analysis of argumentation in the discourse also uses categories of textual order for the study of argumentativity and, more specifically, the controversial modality. Thus, we present the genre of discourse and intertextuality as a possible textual criteria to be mobilized for the analysis of argumentativeness in interactions that participate in the contemporary controversial debate around the two agricultural cultures mentioned above. From the methodological point of view, we chose to analyze a text, belonging to the genre charge, which is part of the controversy on screen. Our analyzes lead us to: i) corroborate the thesis that the option for a given gender consists of a strategy of persuasion and ii) confirm the hypothesis that it is possible for a text without an argumentative purpose to participate actively in a controversy, as long as it is seen from the prism of intertextual relations to which he alludes. Besides these, other textualisation criteria can be mobilized for an analysis of controversial argumentativeness.

Keywords: Controversial mode. Discourse genre. Intertextuality.

\section{Introdução}

Diferente da ideia popularmente aceita de que a polêmica consiste em um modo irracional e violento de debater sobre questões de interesse social, o estudo sistemático que Ruth Amossy (2017[2014]) realizou em torno dessa forma de argumentar atesta a hipótese inicial da analista de que a polêmica preenche funções sociais muito importantes no espaço público das sociedades democráticas pluralistas. Com o intuito de refletir sobre o funcionamento da argumentação no discurso, conforme proposto por Amossy (2005, 2011, 2018[2016]), e sobre uma polêmica atinente ao contexto sociopolítico brasileiro atual, apresentaremos, neste artigo, um exemplo de como categorias de análise utilizadas na Linguística Textual podem servir de parâmetro para o estudo da polêmica. Para isso, optamos por analisar um texto inscrito no debate contemporâneo brasileiro que divide opiniões, grosso modo, em torno de dois modelos agrícolas divergentes: o agronegócio e a agroecologia. 
Iniciaremos por discutir sobre a abordagem da argumentação no discurso, delineada por Amossy (2005, 2011, 2018[2016]) no âmbito dos estudos discursivos contemporâneos de veio não materialista. Nessa ocasião, faremos também uma breve exposição da modalidade argumentativa polêmica, inscrita naquela abordagem, que nos interessa particularmente tanto pela existência de uma investigação sistematicamente avançada sobre ela - cuja publicação brasileira foi intitulada Apologia da polêmica -, como pela circulação massiva, nas mais variadas esferas sociodiscursivas, de textos que comportam essa modalidade. Por fim, exemplificaremos nossa proposta de interface entre Linguística Textual e análise argumentativa do discurso, mostrando como elementos textuais, mais especificamente, a opção por um gênero e as seleções intertextuais, conferem a um texto uma dimensão argumentativa polêmica.

\section{A análise da argumentação no discurso}

A análise argumentativa do discurso (AAD) consiste em uma abordagem voltada para o estudo da argumentação como fenômeno intrínseco ao funcionamento discursivo, que Amossy (2005, 2011, 2018[2016]) propõe ser uma ramificação da Análise do Discurso francesa contemporânea. A AAD toma o princípio dialógico bakhtiniano de linguagem, segundo o qual todo enunciado responde a um jádito (seja para confirmá-lo, refutá-lo ou modificá-lo), e o princípio enunciativo benvenistiano de que toda enunciação tem um propósito de influência sobre o outro como pontos de apoio para a proposição de que a argumentatividade é constitutiva do funcionamento discursivo como um todo.

Diferentemente da concepção retórica de argumentação como a utilização de meios verbais com vistas a provocar ou aumentar a adesão de um auditório às teses que se lhes apresentam ao assentimento (cf. Perelman e Olbrechts-Tyteca, 2005), Amossy (2005, 2011, 2018[2016]) sustenta que nem todo discurso defende expressamente uma tese (e se contrapõe a uma outra), mas que todo discurso busca, ao menos, orientar os modos de ver e de pensar do auditório e, assim, influenciálo. De acordo com a autora, 
v. 9 (1)

$303-320$

jan-abr

2019 preexistente, ela responde necessariamente a indagações que perseguem o pensamento contemporâneo e torna-se objeto tanto de controvérsias em sua forma plena como de discussões atenuadas. Todo enunciado confirma, refuta, problematiza posições anteriores, quer tenham sido expressas de modo preciso por um dado interlocutor, ou de modo difuso no interdiscurso contemporâneo. Tal é a consequência inevitável da natureza dialógica da linguagem [...]. (AMOSSY, 2018[2016], p. 42).

A condição de haver um antagonismo ou uma divergência de posições para haver argumentação nem sempre se observa, explicitamente, nos textos. Em inúmeros casos, a tomada de posição ocorre indiretamente, de modo latente, sob a irremediável manifestação de um ponto de vista. É importante esclarecer que concebemos os termos "tese" /"opinião" e "ponto de vista" distintamente, para nos referirmos, respectivamente, à opinião estrategicamente defendida por um locutor com vistas à sua adesão pelo auditório (trata-se, portanto, de um projeto argumentativo confesso) e à expressão de um modo particular de ver as coisas, que é inerente a todo e qualquer dizer. O ponto de vista é, em outras palavras, uma perspectivização semiotizada, ou uma representação linguageira, de um dado. É este modo discursivamente constitutivo de argumentar que Amossy (2011, 2018[2016]) denomina dimensão argumentativa. A dimensão argumentativa, então, consiste na manifestação de (ao menos) um ponto de vista e abarca inúmeros textos e variados gêneros discursivos, tais como o romance, o poema, o roteiro de viagem, a notícia, o artigo científico etc.

Por outro lado, há o modo expressamente e reconhecidamente persuasivo de argumentar, denominado pela autora de visada argumentativa. Por implicar estratégias argumentativas programadas, somente os textos reconhecidamente argumentativos comportam uma visada, como é o caso típico daqueles que relevam de gêneros opinativos, como o debate eleitoral, a carta aberta, o artigo de opinião, dentre outros.

Movida por pressupostos advindos das ciências da linguagem, na qual ela também se situa, a AAD reorienta a retórica (nova e clássica) e confere, assim, uma amplitude à concepção de argumentação da nova retórica, que foi redefinida por Amossy como

[...] os meios verbais que uma instância de locução utiliza para agir sobre seus alocutários, tentando fazê-los aderir a uma tese, modificar ou reforçar as representações e as opiniões que ela lhes oferece, ou simplesmente orientar suas maneiras de ver, ou de suscitar um questionamento sobre um dado problema. (AMOSSY, 2018[2016], p. 47). 
Mediante a consideração de que todo discurso comporta $a$ priori uma dimensão argumentativa, não seria pertinente manter a distinção corriqueira entre "textos argumentativos" versus "textos não-argumentativos". O que Amossy (2005, 2011, 2018[2016]) propõe, com base nos princípios apontados acima, é que essa dicotomização seja substituída pela ideia de um continuum da argumentatividade, que agregue diversificados graus ou modalidades argumentativas, cada qual com seu regime de racionalidade e de regulação próprios. Estudar essas diversas modalidades argumentativas é uma tarefa à qual se impõe a AAD. Cumpri-la, todavia, requer uma ampliação não só conceitual, mas também metodológica, em relação às retóricas clássica e nova.

Enquanto a nova retórica se ocupa dos "universais argumentativos", a AAD se propõe a desvelar "as modalidades múltiplas e complexas da ação e da interação linguageiras" (AMOSSY, 2018[2016], p. 11), e, para isso, é preciso dotá-la não só das categorias de análise advindas da retórica (ethos, pathos, acordo, auditório, técnicas argumentativas), mas também de dispositivos analíticos utilizados no escopo das ciências da linguagem, especialmente, das disciplinas que compõem a linguística do discurso. Uma das categorias que são caras à $\mathrm{AD}$ francesa contemporânea, da qual deriva a $\mathrm{AAD}$, é a de gênero do discurso.

Segundo Amossy (2011, 2018[2016]), considerar o gênero de discurso no qual a argumentatividade se manifesta, seja em sua visada, seja tão somente em sua dimensão argumentativa, confere à análise da argumentação uma dimensão social e institucional que ultrapassa as análises retóricas que repertoriam universais argumentativos. A nova retórica considera o social na medida em que assume o pressuposto de que a argumentação se baseia em crenças, valores e sentimentos socialmente construídos, assentando-se, por isso, no razoável. O logos retórico, então, é o lugar de uma razão negociada, contingente. A descrição das técnicas argumentativas feita por Perelman e Olbrechts-Tyteca (2005) indica que, de modo geral, a nova retórica preocupa-se com o estudo das ligações operadas por um raciocínio razoável e com sua classificação, ou seja, com os esquemas de raciocínio subjacentes à argumentação, tratando de abstraí-los das realizações linguageiras concretas. A análise retórica, portanto, não se ocupa dos funcionamentos linguageiros propriamente ditos; essa deve ser uma preocupação, de acordo com Amossy (2011, 2018[2016]), dos estudos sobre argumentação realizados no âmbito das ciências da linguagem. A análise da argumentação no discurso pretende 
V. 9 (1)

$303-320$

jan-abr

2019

ir "além da esquematização que restitui um raciocínio abstrato", a fim de "ver como funciona, efetivamente, a estratégia de persuasão em uma situação de comunicação dada" (AMOSSY, 2011, p. 132).

Se o diferencial metodológico entre as teorias retóricas e a abordagem discursiva retoricamente orientada proposta por Amossy reside, principalmente, em considerar a racionalidade implicada nos discursos (ou a colocação dos argumentos em discurso) como sendo situada, diferentemente da razão atemporal das retóricas, é imprescindível tomar a noção de gênero do discurso como critério de análise central na $\mathrm{AAD}$, já que é o gênero, na perspectiva da $\mathrm{AD}, \mathrm{o}$ principal responsável por ligar um texto a um contexto sócio-histórico, interacional e enunciativo. Logo, colocar os argumentos em discurso implica situá-los em um quadro discursivo, que envolve o campo ao qual pertence e o gênero no qual se inscreve a troca verbal (AMOSSY, 2018[2016]). São os quadros discursivos e institucionais que determinam as finalidades da fala, a distribuição dos papéis e a gestão da troca verbal; e, conforme afirma Maingueneau (2008a, 2008b), são os gêneros que refletem a ligação de um texto a um lugar social - daí a sua pertinência para os estudos em AD. Segundo Amossy (2018[2016], p. 245, grifo da autora),

O gênero de discurso é um modelo discursivo que compreende um conjunto de regras de funcionamento e de restrições. Os gêneros são reconhecidos e valorizados pela instituição, segundo princípios variáveis de hierarquização. Eles permitem socializar a fala individual, colando-a em modelos endossados e repertoriados que determinam um horizonte de expectativas. Frequentemente, tem-se notado que, sem a mediação dos gêneros, a interlocução seria impossível: os gêneros autorizam, de fato, a boa recepção de um discurso, orientando a escuta ou a leitura.

É tendo em mente essa concepção de gênero de discurso que Amossy (2011, 2018[2016]) classifica e divide discursos de dimensão argumentativa (notícia, artigo científico, reportagem, autobiografia, histórias de ficção, carta pessoal, conversação cotidiana) e de visada argumentativa (anúncio publicitário, discurso eleitoral, pregação religiosa, manifesto político ou literário). É também considerando traços genéricos que a autora analisa os procedimentos retóricos e discursivos mobilizados na constituição de uma carta aberta e de duas entrevistas eleitorais televisivas (ver AMOSSY, 2018[2016], p. 243-272).

O critério do gênero foi igualmente relevante para a operacionalização da ideia de um continuum da argumentatividade no 
discurso e para a definição das diversas modalidades que lhe constituem. Um continuum que abrigue, em um polo, os discursos marcados pelo choque de teses antagônicas, em outro, aqueles discursos "cujo caráter informativo ou narrativo parece subtrair-lhe toda e qualquer veleidade persuasiva" (AMOSSY, 2018[2016], p. 43), e, entre esses polos, as diversas formas de gestão de conflitos retóricos (declarados ou não), poderia ser assim esquematizado:

Esquema 1 - Continuum das modalidades argumentativas

Choque entre teses antagônicas (modalidade polêmica)

Fonte: elaboração própria.
- Discursos monogeridos que propõem levar o auditório a aderir a uma tese (modalidade demonstrativa);

- Interações face a face em que os participantes negociam um acordo (modalidade negociada); - Situações de diálogo em que os participantes se esforçam para coconstruir uma resposta para uma questão dada (modalidade de coconstrução).
Discursos de caráter informativo ou narrativo (desprovidos de visada argumentativa)

Para definir e exemplificar essas modalidades, Amossy (2008) recorre a traços de gêneros. Assim, negociações comerciais, trocas diplomáticas, audiências de conciliação são gêneros que privilegiam a modalidade negociada; manual escolar, aula, palestra, história de literatura infantil privilegiam a modalidade pedagógica; debate eleitoral, artigo de opinião, fórum de discussão privilegiam a modalidade polêmica. Entendemos, a partir dessa classificação modal, que aquilo que Amossy (2008, 2018[2016]) denomina "discursos" de visada ou, simplesmente, de dimensão argumentativa são, na verdade, textos ${ }^{1}$ que comportam e manifestam variados modos de argumentatividade.

Na subseção que segue, trataremos mais especificamente da modalidade polêmica, que nos tem interessado de perto, por suscitar reflexões bastante profícuas aos estudos do texto.

1 Texto, para nós, é abstração de coerência no sentido de que o cotexto (a superfície material) lhe é parte integrante, mas não representa a integridade textual que se consolida no momento em que um texto é sociocognitivamente processado (produzido ou compreendido), e é unidade concreta da comunicação social no sentido de que se trata de um evento singular, com início e fim (cf. CAVALCANTE, 2016; MACEDO, 2018). 
V. 9 (1)

$303-320$

jan-abr

2019

\section{A modalidade argumentativa polêmica}

Estudar o funcionamento discursivo da argumentatividade requereu de Amossy a elaboração de uma categoria conceitual e operatória que permitisse esclarecer, nas análises, a implicação da situação e do dispositivo de enunciação com o modo particular de verbalização do ponto de vista ou da tese manifestada no e pelo discurso. A noção de "modalidade argumentativa" foi elaborada para atender a essa demanda.

Modalidades argumentativas são estruturas globais de troca argumentativa, são "tipos de troca argumentativa que, atravessando os gêneros do discurso, modelam a forma como a argumentação funciona num quadro tanto dialogal quanto dialógico" (AMOSSY, 2008, p. 232). Essas diferentes maneiras de argumentar são caracterizadas com base nos seguintes parâmetros: i) os papéis desempenhados pelos participantes no dispositivo enunciativo (parceiros, adversários); ii) a maneira pela qual ocorre a tentativa de persuasão (apaixonada, racional, colaborativa, instrutiva); e iii) o modo como o interlocutor é concebido (ser de razão e/ ou de sentimento, aluno ou discípulo, cúmplice ou rival etc.).

Amossy (2008) apresenta algumas possíveis modalidades, apontando gêneros do discurso que as privilegiam, conforme elencamos a seguir:

a) Modalidade demonstrativa: é aquela em que o locutor busca a adesão do(s) interlocutor(es) apresentando uma tese/ uma opinião, em um discurso monogerido ou dialogal, com base em raciocínio apoiado em provas. São exemplos de gêneros nos quais essa modalidade é recorrente: a redação do ENEM, o artigo de opinião, o debate eleitoral, etc.;

b) Modalidade patêmica: é a modalidade caracterizada fundamentalmente pelo apelo explícito aos sentimentos do auditório para angariar sua adesão à tese ou ao ponto de vista apresentado. Estes gêneros privilegiam a modalidade patêmica: o apelo à ajuda humanitária, o poema lírico, a declaração de amor, entre outros;

c) Modalidade pedagógica: é a da transmissão de um saber por um locutor autorizado a fazê-loa um auditório que seencontra na condição de aprendiz. O modo de manifestação dessa troca também pode ser, como nas modalidades anteriores, monogerido ou poligerido. Gêneros como o manual escolar, a aula, a palestra, a história de literatura infantil, entre outros, são exemplos prototípicos de ocorrência dessa modalidade; 
d) Modalidade de coconstrução: é aquela em que os participantes levantam conjuntamente uma questão e, da mesma forma, buscam resolvê-la, por meio de uma interação dialogal. A reunião profissional, a reunião de colegiado, a conversação familiar são exemplos de gêneros que privilegiam essa modalidade;

e) Modalidade negociada: é o tipo de troca em que os participantes debatem sobre um problema que os divide, mas para o qual estão dispostos a buscar e a estabelecer um acordo, por meio de uma negociação das divergências. As negociações comerciais, as trocas diplomáticas, as audiências de conciliação, entre outros, são gêneros que privilegiam a modalidade negociada;

f) Modalidade polêmica: a última modalidade apontada por Amossy (2008) nessa lista éa caracterizada pela confrontação de teses antagônicas, em que se tenta desacreditar o opositor. Ela tornou-se objeto de investigação sistemática em uma pesquisa sobre o discurso polêmico na esfera democrática, realizada por Amossy e sua equipe, da qual derivou a obra Apologie de la polémique (AMOSSY, 2017[2014]), em que nos basearemos para propor uma interface entre AAD e LT.

A primeira e mais marcante característica da polêmica é o choque de opiniões dicotômicas. Enquanto, nas teorias retóricas, o desacordo é parte do circuito da argumentação, mas como uma etapa a ser superada em prol do consenso para a tomada de decisões comuns, na polêmica, ele é pujante, tornando remotas as possibilidades de se chegar a um acordo. Em sociedades democráticas pluralistas, nas quais a liberdade de expressão é tomada como princípio e é constantemente reivindicada em casos de profundas dissonâncias de opiniões, o dissenso² se manifesta abertamente, deixando entrever projetos de sociedade que são inconciliáveis, e "a polêmica preenche funções sociais importantes, precisamente em razão do que é geralmente criticado nela: uma gestão verbal do conflito realizada sob o modo da dissensão" (AMOSSY, 2017[2014], p. 12). Por permitir a coexistência no dissenso, sem que se recorra à violência física, e por preencher outras funções importantes, é que R. Amossy classifica sua obra como uma apologia da polêmica, mais do que um estudo dessa modalidade.

$\overline{2}$ O dissenso/a dissensão é mais do que o desacordo; é "uma profunda, até mesmo violenta, diferença de opiniões" (AMOSSY, 2017[2014], p. 18). 
v. 9 (1)

$303-320$

jan-abr

2019

A segunda característica da polêmica é a polarização social, que consiste na divisão dos sujeitos que participam de uma polêmica em grupos, conforme os papéis que desempenham frente às teses e/ou frente ao próprio debate. Essa divisão ocorre no plano de uma estrutura actancial, na qual se pode exercer o papel de Proponente (aquele cujo papel é defender uma das teses), o de Oponente (aquele cujo papel é opor-se à tese defendida pelo Proponente e defender uma contratese) e o Terceiro (aquele que assiste ao debate). Trata-se de actantes (sujeitos definidos pelos papéis que exercem em uma polêmica) e não de atores (sujeitos empíricos que encarnam os actantes). Como a possibilidade de se chegar a um acordo em uma polêmica é ínfima, Proponente e Oponente jamais se tornarão Parceiros de uma interação em prol de um consenso. É, portanto, ao Terceiro que a argumentação polêmica efetivamente se dirige, na tentativa de persuadilo e de levá-lo a tomar partido de uma ou de outra opinião.

A terceira característica definidora da modalidade polêmica é a desqualificação do outro. Para persuadir o Terceiro, o Proponente não só justifica sua identificação à tese proposta e sua repulsão à oposta, como também desqualifica o Oponente, visto como um adversário que representa o mal e que deve ser discursivamente combatido. O adversário precisa ser deslegitimado para que sua tese também o seja, pois "O descrédito lançado sobre as pessoas anula a força de seus argumentos" (AMOSSY, 2017[2014], p. 59).

A desqualificação pode seguir duas vias: uma centrada no logos e outra, no ethos. A primeira consiste em desacreditar o adversário argumentando pela inadmissibilidade de sua tese e lançando o descrédito sobre seu discurso. Para que esse jogo de refutação seja polêmico, é preciso que o Proponente garanta que o discurso atacado possa ser reconhecido pelo auditório. A segunda, centrada no ethos do Oponente, consiste em desacreditar o adversário atacando diretamente sua imagem, representativa do grupo com o qual ele se identifica. A desqualificação pode incidir sobre o grupo que ele representa ou sobre a pessoa do Oponente (que, a nosso ver, sendo concebida como uma peça daquela estrutura actancial de que falamos anteriormente, consiste também em uma desqualificação, ainda que indireta ou implícita, do grupo ao qual ele pertence).

De acordo com Amossy (2017[2014]), ao contrário do que comumente se pensa, a violência verbal e as emoções não são traços primários da modalidade polêmica; são características secundárias, decorrentes das três principais que acabamos de apontar. 
Feitas essas considerações, podemos afirmar que, na perspectiva da $\mathrm{AAD}$, para que um texto apresente a modalidade argumentativa polêmica, é preciso que ele mostre indícios de: a) um confronto de opiniões antagônicas e inconciliáveis; b) uma polarização social, dividindo os debatedores entre Proponentes e Oponentes que tentam persuadir o Terceiro; e c) uma tentativa de desqualificar o Oponente. Por esse prisma, de fato, a modalidade polêmica deveria se manifestar tão somente em textos que comportassem visada argumentativa, conforme previu Amossy (2011).

Na próxima seção, justificaremos nossa tentativa de estabelecer um diálogo entre a LT e a AAD e buscaremos exemplificar esse diálogo por meio de uma análise do funcionamento textual da polêmica, encetada há alguns anos no Brasil, em torno de dois modelos agrícolas divergentes: a agroecologia e o agronegócio.

\section{Parâmetros textuais de análise da modalidade polêmica}

A análise da argumentação no discurso insiste tanto no princípio geral de que a argumentatividade é inerente ao funcionamento discursivo como no princípio específico de que é no nível de sua construção textual que a argumentação deve ser estudada. Os parâmetros de análise da $\mathrm{AAD}$ estão, atualmente, centrados em categorias de ordem pragmática (como os implícitos, pressupostos e subentendidos) e linguística (termos lexicais de modo geral, modalizadores, conectores e construções sintáticas). Nosso intuito, desde nossa tese (MACEDO, 2018), é contribuir, com critérios analíticos da LT, para a investigação das estratégias por meio das quais a argumentatividade retórico-discursiva pode se inscrever em textos. Pensamos, em consonância com Cavalcante (2016), que categorias de ordem textual, tais como intertextualidade, plano de texto, sequências textuais, referenciação, topicalidade, dentre outros, podem ampliar as possibilidades de desvelamento da argumentatividade em situações concretas de uso da linguagem, cooperando, assim, para o estudo dos funcionamentos discursivos de modo geral e, em especial, da modalidade argumentativa polêmica.

Optamos, do ponto de vista metodológico, por ilustrar esta nossa proposta de diálogo por meio da análise de um texto que consideramos fazer parte da polêmica em torno das culturas agrícolas denominadas "agronegócio" e "agroecologia". Fizemos também a opção por dois parâmetros de análise bastante caros aos estudos do texto: gênero do discurso e intertextualidade. 
v. 9 (1)

303-320

jan-abr

2019

Antes de iniciarmos a análise, é indispensável contextualizar a polêmica da qual o texto participa, ainda que indiretamente, e destacar a importância da figura do jornalista e das mídias na veiculação e espetacularização das polêmicas contemporâneas. Aliás, o papel do jornalista é importante não só para esses fins; ele constrói a polêmica,

[...] no sentido de que ele constrói um diálogo virtual entre partes que se pronunciam numa rica variedade de ditos e de escritos. Ele seleciona, ordena e produz uma troca virtual entre os representantes dos prós e dos contras - aqueles que tiveram entre si trocas diretas e aqueles que não tiveram. Ele faz repercutirem as falas dos atores sociais que seleciona, dividindo-os em dois campos opostos - o do Proponente e o do Oponente. Ele permite, assim, que o leitor se reconheça na massa dos discursos que circulam no espaço público, estruturando essa massa e fazendo com que ela faça sentido para o leitor. Nunca é demais, nessa perspectiva, superestimar o papel do jornalista. Ele lança a polêmica, dando-lhe publicidade, e lhe confere o estatuto de acontecimento; constrói, com a ajuda das diferentes formas de discurso reportado, um diálogo virtual entre detentores de posições em conflito; põe em evidência os blocos de argumentos que estruturam o debate; e contribui para orientá-lo por meio de suas intervenções diretas ou indiretas. (AMOSSY, 2017[2014], p. 202).

É exatamente isso o que fazem os jornalistas nas reportagens intituladas "Veneno x salvação da lavoura: da plantação até sua mesa, saiba quais são os argumentos sobre a mudança na legislação dos agrotóxicos", escrita por Diego Toledo3, e "Entenda o que está em jogo na nova lei dos agrotóxicos", atribuída a Karina Campos, com edição de Cassiano Ribeiro4. Nessas reportagens, os locutores não assumem expressamente uma posição, apenas cumprem com o papel (institucionalizado na e pela esfera jornalística) de informar o leitor sobre uma polêmica que atravessa o Brasil há tempos, mas que foi insuflada pela então iminente aprovação do Projeto de Lei no 6.299/2002 na Câmara dos Deputados, dando a conhecer os dois lados que debatem e que se dividem, grosso modo, entre as teses de que o agronegócio (e o uso de agrotóxicos) é uma cultura apropriada ao país e a de que a agroecologia (sem a utilização de agrotóxicos) é a melhor opção.

O texto que vamos analisar instancia o gênero charge e releva da esfera midiática. Trata-se de um gênero constitutivamente intertextual, na medida em que a charge corresponde necessariamente a

3 Disponível em https://www.uol/noticias/especiais/agrotoxicos-pl-do-venenopropostas-argumentos.htm\#veneno-x-salvacao-da-lavoura Acesso em 04/10/2018.

4 Disponível em https://revistagloborural.globo.com/Noticias/Agricultura/ noticia/2018/06/entenda-o-que-esta-em-jogo-na-nova-lei-dos-agrotoxicos.html Acesso em 04/10/2018. 
uma resposta, crítica e cômica, a notícias, reportagens ou outros textos jornalísticos que veiculam informações relacionadas a acontecimentos e/ou a temas sociais, políticos e econômicos. A temporalidade do gênero também é, ao menos em parte, definida pelo campo jornalístico: uma charge produzida há anos pode ser retomada e voltar a circular por ocasião de um acontecimento pontual noticiado pela imprensa, que reacende, assim, o debate em torno de uma questão social encetada outrora. Atualmente, com a popularização da Internet e, principalmente, com a vulgarização das redes sociais e dos aplicativos de mensagens instantâneas, o espaço privilegiado de publicação e de circulação das charges deixou de ser os jornais impressos e passou a ser, massivamente, as telas dos dispositivos eletrônicos.

O texto abaixo é uma charge produzida pelo cartunista Kayser e publicada, em janeiro de 2012, pelo próprio autor, na página denominada Blog do Kayser. Trata-se, explicitamente, de uma resposta do cartunista a duas matérias publicadas, no mesmo período, por duas revistas de informação de grande circulação nacional: as revistas Veja e Época.

Exemplo - Charge de Kavser

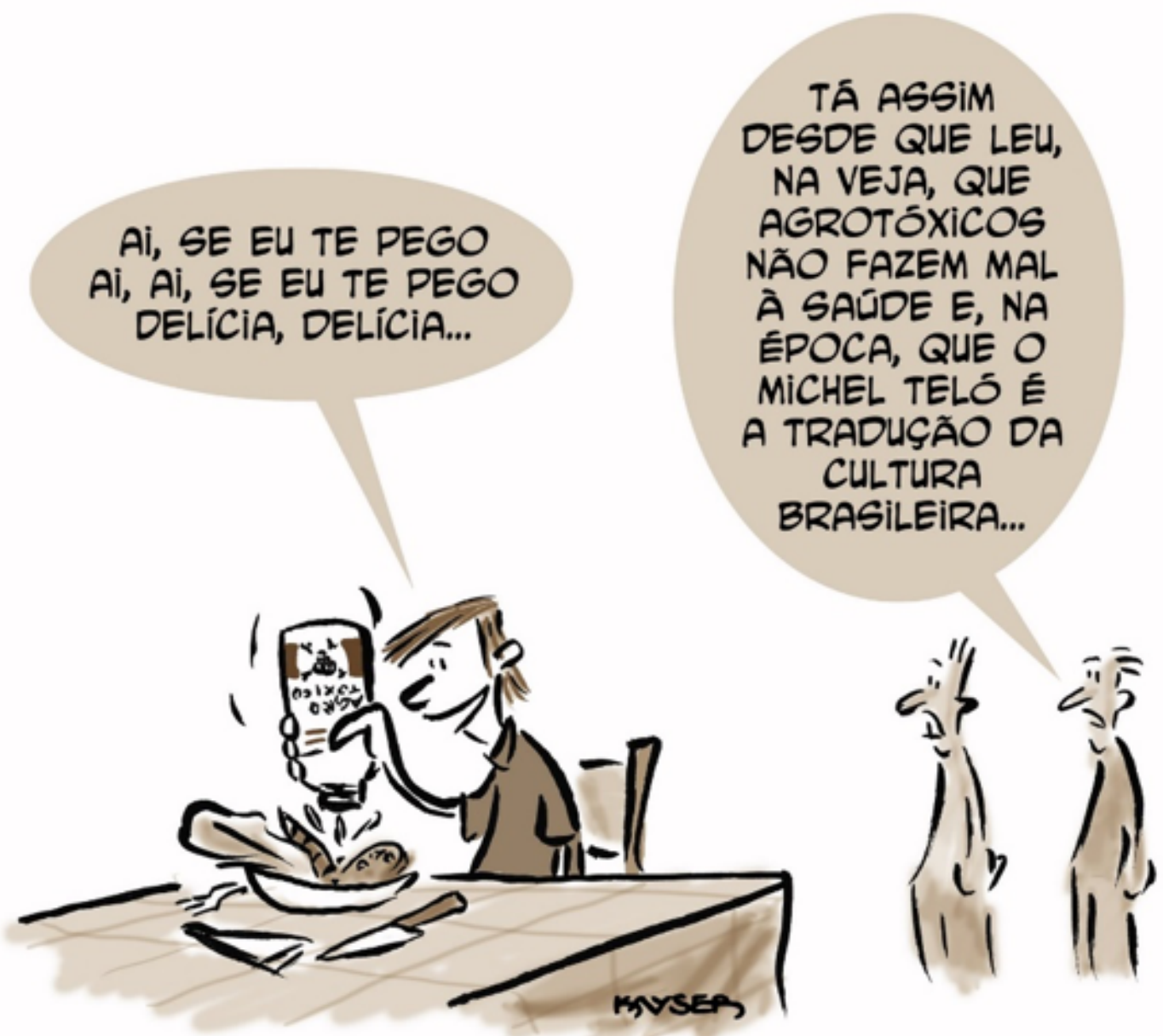

Fonte: http://blogdokayser.blogspot.com/search/label/Agrot\%C3\%B3xico Acesso em 04/10/2018. 
V. 9 (1)

$303-320$

jan-abr

2019

Do ponto de vista técnico-retórico, o locutor desse texto baseia sua argumentação, em um plano de fundo (que considera somente a fala que consta no segundo balão), no argumento de reciprocidade, que supõe a existência de uma simetria entre atos, entre acontecimentos ou entre seres, de modo que essa relação simétrica realize uma assimilação de situações (PERELMAN e OLBRECHTS-TYTECA, 2005, p. 250-251). Ainda de acordo com Perelman e Olbrechts-Tyteca (2005, p. 253),

Por vezes a identificação de situações resulta de que dois atos, mesmo sendo distintos, concorreram para um mesmo efeito (...). Duas condutas complementares, no sentido de que constituem ambas uma condição necessária à realização de um determinado efeito, podem dar azo à utilização do argumento de simetria.

É o que faz o locutor dessa charge quando escreve, no segundo balão: "Tá assim desde que leu, na Veja, que agrotóxicos não fazem mal à saúde e, na Época, que o Michel Teló é a expressão da cultura brasileira...". Ao atribuir à conduta excêntrica da personagem que ocupa a posição de figura no quadrinho a motivação de ter sido influenciada por informações veiculadas por dois grandes veículos de comunicação ${ }^{5}$, o locutor do texto coloca as duas publicações como sendo duas condutas que se assimilam (de modo que a tese de que Michel Teló é a expressão da cultura brasileira é uma tese tão tola quanto a de que agrotóxicos não fazem mal à saúde) para produzir um mesmo efeito: manipular (e imbecilizar) seus leitores. A atitude da personagem que cantarola a música pela qual Michel Teló se tornou um cantor internacionalmente conhecido, enquanto coloca veneno em seu sanduíche, representa um apelo ao ridículo como meio de persuadir o leitor da charge. Trata-se de buscar sancionar pelo riso, pelo humor, a ideia de que uma regra de comportamento (não se deve consumir veneno, a menos que se queira adoecer ou morrer) foi transgredida por um comportamento excêntrico, mas não perigoso o suficiente para que seja reprimido com virulência. É, então, por meio do apelo ao ridículo e do argumento de reciprocidade que o locutor dessa charge deixa entrever seu posicionamento na polêmica em questão: ele exprime, de maneira enviesada, o ponto de vista contrário à utilização de agrotóxicos nas plantações, prática assimilada ao agronegócio no Brasil.

\footnotetext{
5 É possível acessar o conteúdo da matéria da Veja no site https://pt.slideshare.net/ VivianblasoBlaso/a-verdade-sobre-os-agrotoxicos-veja-04012012.
} 
Sob a perspectiva textual, podemos dizer que a opção pelo gênero charge consiste, em si mesma, em uma estratégia de persuasão, na medida em que esse gênero tem como temática privilegiada questões relativas à sociedade, à política, à economia, lançadas a público pelo campo jornalístico (que, conforme vimos, exerce papel fundamental na propulsão de polêmicas), e na medida em que é monogerido, podendo o cartunista expressar seu ponto de vista sem a interveniência direta de um opositor. O conteúdo temático do gênero é, portanto, um vetor de intertextualidade.

No caso da charge em tela, há remissão a dois textos-fonte específicos: duas matérias publicadas pelas revistas Veja e Época, em relação às quais o cartunista se posiciona, por meio das estratégias retóricas descritas anteriormente. Por meio de uma seleção intertextual, o locutor institui e materializa, implicitamente, os traços definidores da modalidade polêmica: a) as duas teses em jogo na polêmica sobre o uso de agrotóxicos que, a reboque, é também uma polêmica em torno das teses que dividem as culturas agrícolas entre agronegócio e agroecologia; b) os dois posicionamentos possíveis em relação a essas teses, quais sejam, o de que os agrotóxicos são inofensivos e, portanto, o agronegócio não oferece risco à saúde humana, e o de que os agrotóxicos são perigosos e, portanto, a cultura agrícola ideal é a agroecologia, que não se utiliza desse método de combate às pragas; e c) ridiculariza quem aceita a primeira tese como razoável e, assim, desqualifica o Oponente da tese segundo a qual os agrotóxicos são perigosos. Apesar de não comportar uma visada argumentativa, pois não há a expressão manifesta de uma opinião, é possível abstrairmos desse texto os traços da modalidade polêmica. Essa abstração, no entanto, só é viabilizada por uma relação entre textos. Tal constatação nos leva a afirmar que "a polêmica emerge sempre de uma relação intertextual" (CAVALCANTE, 2017):

Sem dúvida, a polêmica é um modo de gestão do conflito entre discursos opostos. Mas, se Amossy afirma que ela se dá a partir de casos concretos e que é efêmera, é porque ela emerge de textos, de eventos concretos, únicos e irrepetíveis.

Somente na relação entre textos é que se pode compreender o conflito entre discursos. (CAVALCANTE, 2017).

Quanto ao estilo, a charge se faz compreensível a uma gama considerável de leitores, por sua linguagem quase sempre bastante acessível, sem rebuscamentos e com estruturas sintáticas que permitem aos interlocutores em geral (re)construir os possíveis sentidos do texto. Esse estilo permite, portanto, alcançar um auditório variável e amplo. 
v. 9 (1)

303-320

jan-abr

2019

A estrutura composicional típica desse gênero é marcada pela multimodalidade e por uma plurissequencialidade, em que uma narrativa é construída em torno de um período explicativo, que pode ser representado pela seguinte estrutura, dentre outras (ADAM, 2011[2008], p. 238): [SE p, É PORQUE q]. A proposição-enunciado do segundo balão explica o motivo da excentricidade do comportamento da personagem em foco. O acontecimento representado no quadrinho poderia ser formalmente reduzido ao seguinte período explicativo: SE fulano anda consumindo veneno junto à alimentação e cantando "Ai, se eu te pego...", É PORQUE "ele leu, na Veja, que agrotóxicos não fazem mal à saúde e, na Época, que o Michel Teló é a tradução da cultura brasileira...". Conforme assinala Adam (2011[2008], p. 243), "A asserção das proposições p e q não tenta adequar-se a um estado do mundo; ela tenta que o mundo seja visto pelo leitor-ouvinte potencial de acordo com a crença proposta pelo enunciador". A isso, o autor ajunta:

Como o objetivo último do compartilhamento de crenças é um objetivo de ação, a explicação aparece como um ato intermediário entre o objetivo ilocucionário primário da asserção (partilhar uma crença ou um conhecimento) e o objetivo último do ato (convencer para fazer agir). (ADAM, 2011[2008], p. 243).

Tendo analisado como esse texto de Kayser instancia características relativas ao tema, ao estilo e à estrutura composicional do gênero charge, e como as relações intertextuais, previstas pela prototipicidade desse gênero, autorizam um posicionamento em um debate polêmico, reiteramos nossa proposta de que categorias textuais de análise sejam agregadas aos dispositivos já eleitos por Amossy (2018[2016]) para o estudo da argumentação no discurso.

\section{Considerações finais}

A opção por um dado gênero e as seleções intertextuais, critérios de que lançamos mão para descrever o funcionamento textual de uma charge, dão prova de que a LT tem a contribuir, com seus parâmetros de análise, com a abordagem da argumentação no discurso. Se Amossy coloca como tarefa de sua proposta o estudo das "modalidades múltiplas e complexas da ação e da interação linguageiras" (AMOSSY, 2018[2016], p. 11) e o desvelamento dos funcionamentos discursivos da linguagem situada, do modo como esses funcionamentos se aliam à retórica nos mais variados textos, pertencentes aos mais variados 
campos da atividade humana e aos mais variados gêneros, então, a LT pode estabelecer uma interface profícua com a $A D$ no sentido de analisar a argumentatividade inscrita nos textos.

Nosso estudo demonstrou que a instanciação do gênero charge, no texto produzido por Kayser, consistiu em uma estratégia textual de persuasão, pois o conteúdo temático do gênero permitiu ao autor utilizar de uma técnica retórica e manifestar, ainda que enviezadamente, seu posicionamento sobre a questão polêmica relativa aos modos de agricultura adotados no Brasil. Por outro lado, a seleção intertextual feita pelo autor instituiu e materializou as teses antagônicas em torno dessa polêmica, os posicionamentos possíveis mediante essas teses e a desqualificação do Oponente pela ridicularização de sua tese.

Pudemos concluir, com base nos resultados da análise, que a abordagem da argumentação no discurso amplia consideravelmente as possibilidades de compreensão da argumentatividade e, mais especificamente, do fenômeno sociodiscursivo da polêmica. Quanto à interface entre a LT e a $\mathrm{AAD}$, os parâmetros textuais de análise cotejados neste trabalho corroboram com nossa hipótese inicial de que a LT pode oferecer contribuições significativas à análise da argumentação no discurso.

\section{Referências}

$A D A M$, Jean-Michel. A linguística textual: introdução à análise textual dos discursos. Trad. João Gomes da Silva Neto et al. 2.ed. rev. e aum. São Paulo: Cortez, 2011[2008].

AMOSSY, Ruth. Rhétorique et analyse du discours. Pour une approche sociodiscursive des textes. In: ADAM, J.M.; HEIDMANN, U. (Orgs.). In: Sciences du texte et analyse de discours. Etudes de Lettres, 2005, p. 163-179.

As modalidades argumentativas do discurso. In: LARA, Gláucia; MACHADO, Ida; EMEDIATO, Wander (Orgs.). Análises do discurso hoje, vol. 1. Rio de Janeiro: Nova Fronteira, 2008, p. 231-254.

Argumentação e Análise do Discurso: perspectivas teóricas e recortes disciplinares. Trad. Eduardo Lopes Piris e Moisẻs Olímpio Ferreira. In: EID\&A - Revista Eletrônica de Estudos Integrados em Discurso e Argumentação, Ilhéus, n. 1, nov. 2011, p. 129-144.

Apologia da polêmica. Trad. Mônica Magalhães Cavalcante et al. São Paulo: Contexto, 2017[2014].

A argumentação no discurso. Coord. de trad. Eduardo Lopes Piris e Moisés Olímpio-Ferreira; trad. Angela M. S. Corrêa et al. São Paulo: Contexto, 2018 [2016]. 
V. 9 (1)

$303-320$

jan-abr 2019

CAVALCANTE, Mônica Magalhães. Abordagens da argumentação nos estudos de Linguística Textual. In: ReVEL, edição especial, vol. 14, n. 12, 2016, p. 106 124 .

$\overline{\mathrm{RN}}, 2017$.

Linguística Textual e Argumentação. Encontro do GELNE. Natal/

MACEDO, Patrícia Sousa Almeida de. Análise da argumentação no discurso: uma perspectiva textual. 243f. Tese (Doutorado), Universidade Federal do Ceará, Centro de Humanidades, Programa de Pós-Graduação em Linguística, Fortaleza, 2018.

MAINGUENEAU, Dominique. Análise de textos de comunicação. Trad. Cecília P. de Souza-e-Silva. 5.ed. São Paulo: Cortez, 2008a.

Discurso e análise do discurso. In: SIGNORINI, Inês (Org.). [Re] discutir texto, gênero e discurso. São Paulo: Parábola Editorial, 2008b, p. 135-155.

PERELMAN, Chaïm; OLBRECHTS-TYTECA, Lucie. Tratado da argumentação: a nova retórica. Trad. Maria Ermantina de Almeida Prado Galvão. 2.ed. São Paulo: Martins Fontes, 2005. 